\title{
OPTIMAL TRADEOFFS BETWEEN THE SECURITY AND COST OF CRITICAL BUILDINGS AND INFRASTRUCTURE SYSTEMS
}

\author{
STEVEN SCHULDT \& KHALED EL-RAYES \\ Department of Civil and Environmental Engineering, University of Illinois at Urbana-Champaign, \\ Urbana, IL, USA.
}

\begin{abstract}
Explosive terrorist attacks targeting critical buildings and infrastructure systems pose a formidable threat worldwide, having caused 12,425 casualties and \$20 billion in direct economic losses in 2015 alone. Designers of these critical buildings attempt to minimize the security risks to site personnel and buildings by analyzing and selecting the most effective combination of: (1) increasing the standoff distance between site assets and potential locations of explosive attacks; (2) constructing blast-mitigating perimeter walls; and (3) hardening site facilities. To support designers in this critical and challenging task, this paper presents the development of a multi-objective optimization model capable of generating optimal tradeoffs between minimizing total site destruction levels and minimizing site construction costs. The model computations are performed utilizing the nondominated sorting genetic algorithm II (NSGA-II) because of its proven capability in modeling non-linear objective functions and constraints, and its successful modeling of previous facility layout problems. The model performance was evaluated using a case study of a hypothetical military forward operating base, and the results illustrated the novel capabilities of the developed model in identifying design configurations that generate optimal tradeoffs between the aforementioned optimization objectives. These capabilities are expected to support designers in their ongoing efforts to construct cost-effective sites that minimize the security risks to personnel and buildings from the threat of explosive terrorist attacks.
\end{abstract}

Keywords: blast effects, blast wall, critical infrastructure, facility layout, genetic algorithms, optimization, security

\section{INTRODUCTION}

Explosive terrorist attacks targeting critical buildings and infrastructure systems pose a formidable threat worldwide, having caused 12,425 casualties and \$20 billion in direct economic losses in 2015 alone [1,2]. Accordingly, developing optimal site layout and security plans for critical buildings and infrastructure projects is essential to minimize the destruction caused by an explosive terrorist attack. The most cost-effective design solution to minimize building destruction levels is to increase the standoff distance between site assets and the closest possible explosive location [3]. When the available standoff distance does not provide the desired level of protection for the anticipated explosive threat, designers must utilize a combination of constructing blast-mitigating perimeter walls and hardening site buildings [4]. Designers of critical building and infrastructure projects face the challenging task of selecting the optimal design configuration that provides the desired level of protection while adhering to a limited construction budget in a confined site space. Therefore, designers must carefully analyze all feasible design alternatives and select the optimal combination of perimeter blast walls, building locations, and building materials that minimizes site destruction levels from an explosive attack while minimizing site construction costs.

Previous models and research studies evaluated the blast-mitigating capabilities of various blast wall materials [5-10] and attempted to optimize the layout of site facilities to improve site security [11-13]. Despite their contributions, these studies do not provide the capability to optimize the layout of site buildings and the selection of perimeter blast walls and building 
materials in order to minimize total site destruction levels from an explosive attack. Accordingly, the main objective of this study is to present the development of a new multi-objective optimization model capable of generating site layout and security planning design solutions that represent optimal tradeoffs between minimizing total site destruction levels from an explosive attack and minimizing site construction costs.

The following sections of the paper describe: (i) formulating the multi-objective optimization model; (ii) identifying the required model input data; and (iii) evaluating model performance on an application example.

\section{MULTI-OBJECTIVE OPTIMIZATION MODEL FORMULATION}

The present model utilizes the nondominated sorting genetic algorithm II (NSGA-II) [14] to optimize the site layout and security decisions for critical building and infrastructure systems to minimize total site destruction levels while minimizing site construction costs. The development of this model includes identifying model decision variables, formulating the destruction and cost objective functions, and integrating facility layout constraints.

\subsection{Model decision variables}

The decision variables utilized in the present model are designed to represent the site layout and security decisions that have an impact on site destruction levels suffered from an explosive attack and site construction costs. Accordingly, the model considers two main types of decision variables: (1) perimeter blast wall decision variables; and (2) building decision variables. First, perimeter decision variables consist of the perimeter blast wall location (PL), blast wall type $(\mathrm{T})$ and blast wall height $(\mathrm{H})$. Second, building decision variables include the selected building material $\left(\mathrm{M}_{\mathrm{i}}\right)$, building location $\left(\operatorname{Loc}_{\mathrm{i}}\right)$, and building orientation $\left(\theta_{\mathrm{i}}\right)$, as shown in Fig. 1.

The model employs a user-specified grid system that allows planners to set their preferred grid spacing. Building locations are then defined by the placement of their centroids on the grid system and the building orientation is the degree that the building is rotated about its centroid. Building location 1 (grid coordinate 44) in Fig. 1 shows two possible building rotation angles for a single building, where the blue building represents a $0^{\circ}$ orientation and the orange building represents a $90^{\circ}$ orientation.

\subsection{Model objective functions}

The first objective function in the present model is designed to minimize the destruction of site buildings caused by an explosive attack. This objective function is quantified as the site destruction level (DL) index that ranges from $0 \%$, which represents no building destruction, to $100 \%$, which represents the complete destruction of all buildings on site, as shown in eqn (1). DL is represented as a weighted average of the destruction level suffered by all buildings on site and is calculated by summing up all the products of the damage level of each building and its importance weight $\left(\mathrm{w}_{\mathrm{i}}\right)$, which is assigned by designers to designate buildings that are most critical to the site mission. The damage level of each building is calculated using a recently developed model for quantifying blast effects on facilities behind blast walls [15]. Beginning at the blast center, this developed methodology computes the distances from the blast location at which five decreasing levels of building destruction occur (severe, heavy, moderate, minor, and minimal) for each unique design combination of blast charge weight, 


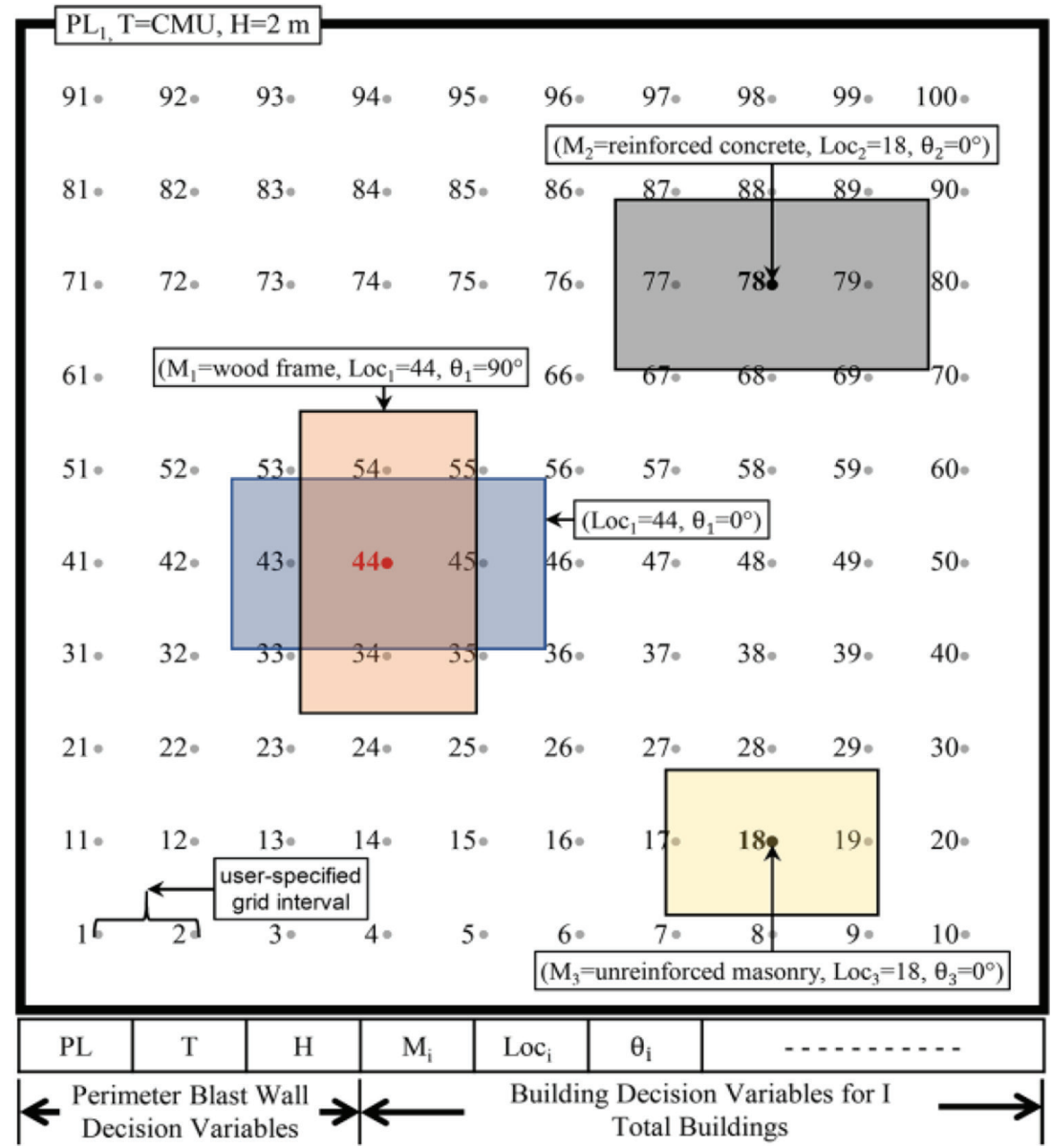

Figure 1: Model decision variables.

perimeter blast wall location, type, and height, and building material. Next, the model automatically computes the percent area of each building within each of these five damage levels $\left(P B A_{i, j}\right)$. The building damage level is then computed by taking the sum of the $P B A_{i, j}$ multiplied by the level of building destruction associated with each damage level $\left(P D_{j}\right)$, as defined by existing blast design manuals $[4,16]$.

$$
\text { minimize } D L=\sum_{i=1}^{I} \sum_{j=1}^{5} P B A_{i, j} \times P D_{j} \times w_{i}
$$

where $D L=$ total site destruction level $(0-100 \%)$;

$i=$ building number;

$I=$ total number of buildings on site;

$j=$ damage level;

$P B A_{i, j}=$ percent area of building $\mathrm{i}$ within damage level $\mathrm{j}(\%)$;

$P D_{j}=$ percent building destruction caused by damage level $\mathrm{j}(\%)$; and

$w_{i}=$ importance weight for each building $\mathrm{i}$, where $w_{i}>0$ and $\sum_{i=1}^{I} w_{i}=1$. 
The second optimization objective is minimizing site construction costs (SC). SC is calculated as the sum of building construction costs (BC), perimeter blast wall construction costs (WC) and future wall replacement costs (WR), as shown in eqn (2). It is necessary to include wall replacement costs when the site operational lifespan is longer than the expected design life of the selected wall type. For example, sand-filled containers typically have a design life of 3-5 years. Furthermore, a discount factor is applied to the wall replacement costs to compute the present value of the future construction costs.

$$
\text { minimize } S C=B C+W C+W R
$$

where $S C=$ total site construction cost (present year $\$$ );

$B C=$ construction cost of all buildings on site $(\$)$;

$W C=$ perimeter blast wall construction cost $(\$)$; and

$W R=$ present value of future year wall replacement cost $(\$)$.

\subsection{Model constraints}

The model is designed to comply with all practical geometric constraints to guarantee the feasibility of generated layout solutions by ensuring: (1) all buildings are constructed within the site perimeter; (2) buildings do no overlap one another; (3) minimum separation distances between buildings are established to comply with applicable security and safety requirements; and (4) maximum separation distances between buildings are established to comply with applicable mission requirements.

\section{MODEL INPUT DATA}

Designers of critical buildings and infrastructure systems projects are required to collect and provide all building, perimeter blast wall, site, and explosive threat data. Additionally, designers must specify all search parameters for the multi-objective genetic algorithm. Building data defines: (1) dimensions of building(s) footprint; (2) designer-specified building importance weights; (3) available building materials; and (4) unit construction cost for each building material $\left(\$ / \mathrm{m}^{2}\right)$. Perimeter blast wall data includes: (1) feasible location(s) for the perimeter blast wall; (2) available blast wall types; (3) optional heights for each blast wall type; (5) design life for each blast wall type; (6) unit construction cost of each wall type (\$/m); and (7) unit cost to remove and replace each blast wall type $(\$ / \mathrm{m})$. Site data consist of the: (1) dimensions of the available site area; (2) anticipated site operational lifespan; (3) construction area cost factor based on the site location; and (4) discount factor to present all costs in present-year dollars. Explosive threat data define the explosive charge weight(s) to be evaluated and should be selected based upon local intelligence and any historical attack data for the project area. The genetic algorithm search parameters define the population size, number of generations, mutation rate, crossover type and crossover rate. For site layout optimization models using NSGA-II, the following parameters are recommended to provide near-optimal results with practical computational times: population size ranging from 5 to 10 times the total number of decision variables; number of generations approximately 10 times the number of decision variables; mutation rate between 0.001 and 0.1 , multi-point crossover, and a crossover rate between 0.5 and 0.9 [17]. 


\section{APPLICATION EXAMPLE}

The performance of the developed site layout and security planning optimization model is evaluated using an application example of the construction of a 100-person military forward operating base. The input data required for this example includes: (1) building data; (2) perimeter blast wall data; (3) site characteristics; (4) threat data; and (5) genetic algorithm search parameters. First, building data includes the dimensions and importance weights for the 11 buildings to be constructed on site, as shown in Table 1, as well as the construction cost per square meter for each of the six available building materials. Second, perimeter blast wall data consists of the height, design life, and the initial construction and replacement costs per linear meter for 15 feasible blast wall types. Third, site characteristics include an available site area of 90 meters x 60 meters, an anticipated site operational lifespan of 30 years, and a construction area cost factor of 1.55 based on the site location [18]. Fourth, the application example analyzed a $250 \mathrm{~kg}$ explosive threat, which represents the design blast charge weight carried in a sport utility vehicle [3]. Fifth, the genetic algorithm search parameters utilized in this application example are a population size of 150, 600 generations, a mutation rate of 0.01, two-point crossover, and a crossover rate of 0.75 . These parameters were selected by analyzing the optimization performance of a large number of experiments that evaluated a wide range of the aforementioned optimization parameters.

The number of decision variables and their feasible input values results in a large search space of 21.4 million possible solutions, where each solution represents a unique combination of site layout and security decisions. The optimization model was utilized to search this large and highly constrained solution space in order to identify near-optimal solutions. Accordingly, the model generated a wide spectrum of 45 Pareto-optimal (i.e. nondominated) solutions, where each solution represents a unique and optimal tradeoff between the two optimization objectives of minimizing total site destruction and minimizing site construction cost, as shown in Fig. 2. The generated pareto-optimal solutions range from a minimum destruction level of $8.11 \%$ at a maximum construction cost of $\$ 6.50$ million (solution S1) to a minimum construction cost of $\$ 3.96$ million with an expected destruction level of $53.9 \%$ (solution S45).

Table 1: Sample building input data.

\begin{tabular}{lllll}
\hline \multicolumn{3}{c}{} & Dimensions & \\
\hline ID & Description & Length $(\mathrm{m})$ & Width $(\mathrm{m})$ & $\begin{array}{l}\text { Importance } \\
\text { weight }\left(\mathrm{w}_{\mathrm{i}}\right)\end{array}$ \\
\hline F1 & Dormitory & 15 & 10 & 0.10 \\
F2 & Dormitory & 15 & 10 & 0.10 \\
F3 & Dormitory & 15 & 10 & 0.10 \\
F4 & Dormitory & 15 & 10 & 0.10 \\
F5 & Kitchen and dining facility & 12 & 9 & 0.05 \\
F6 & Communications building & 8 & 8 & 0.15 \\
F7 & Headquarters & 12 & 6 & 0.15 \\
F8 & Senior leader dormitory & 15 & 10 & 0.10 \\
F9 & Storage & 8 & 8 & 0.01 \\
F10 & Maintenance & 8 & 8 & 0.04 \\
F11 & Emergency response & 12 & 9 & 0.1 \\
\hline
\end{tabular}




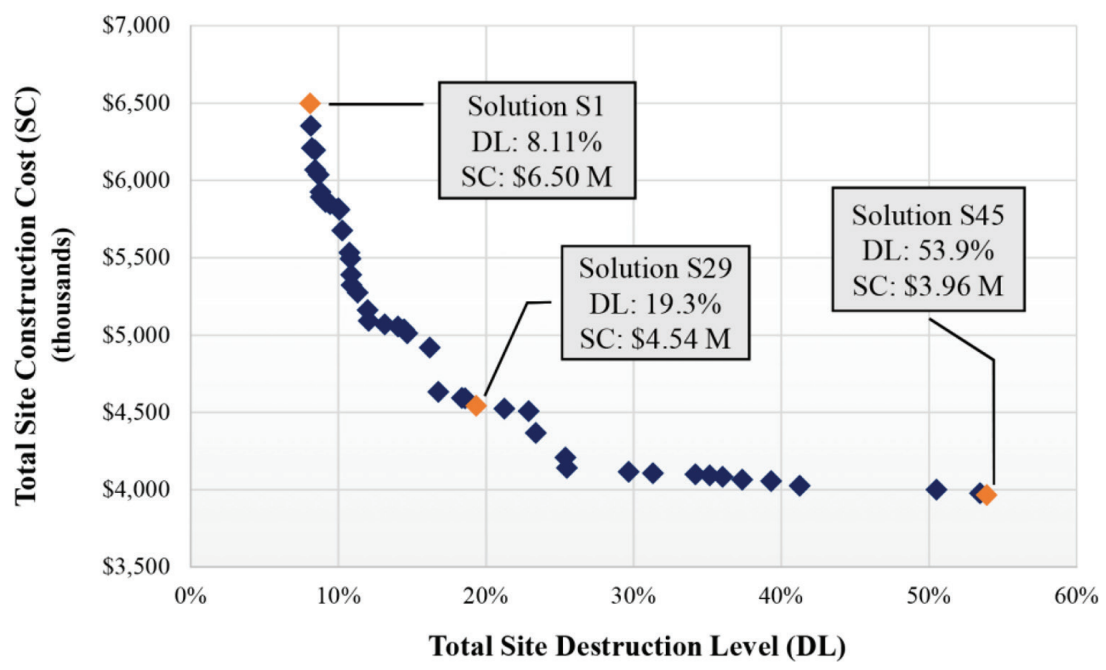

Figure 2: Generated Pareto-optimal solutions.

The minimal destruction level solutions (S1) is achieved by selecting the perimeter blast wall type and building materials that provide the greatest levels of blast mitigation and resistance: a five-meter tall, thick sand blast wall and buildings constructed of steel frame with lightly reinforced CMU infill walls or reinforced concrete with lightly reinforced CMU infill walls, as shown in Fig. 3. At the other end of the spectrum, the minimal cost solution is achieved by constructing the most inexpensive perimeter blast wall type considering the site's 30-year lifespan, a two-meter-tall, thin precast concrete panel wall and utilizing the most inexpensive building materials, wood-frame and pre-engineered metal construction. Between these two ends of the spectrum, the model generated 43 other nondominated solutions that

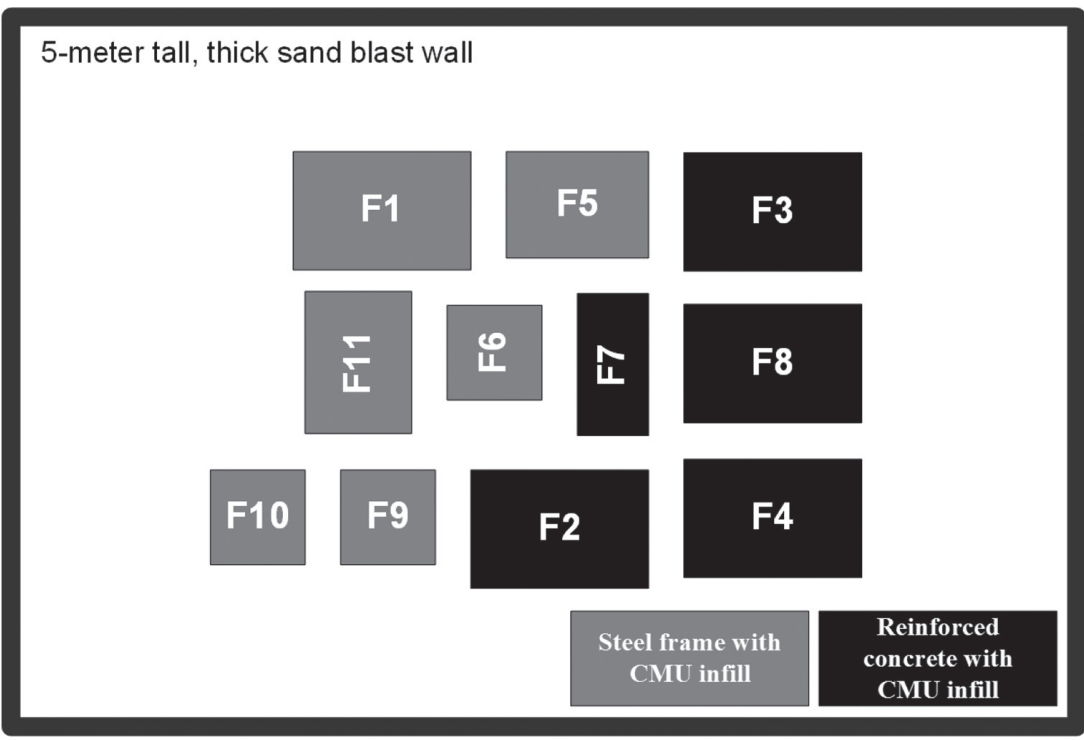

Figure 3: Site layout plan with the lowest total site destruction level (S1). 
designers can select based on their maximum acceptable site destruction level in the event of an explosive attack and their maximum available construction budget. For example, the design that results in the lowest possible construction cost ( $\$ 4.54$ million) where the maximum acceptable destruction level is set to $20 \%$ is identified as solution S29 in Fig. 2.

\section{SUMMARY AND CONCLUSIONS}

This paper presented the development of a new multi-objective optimization model capable of optimizing the site layout and security planning of critical building and infrastructure systems in order to simultaneously reduce site destruction levels in the event of an explosive terrorist attack and reduce site construction costs. An application example was evaluated in order to highlight the significance and usefulness of the developed model. The model was able to efficiently search a large solution space and identify 45 near-optimal site layout and security plan solutions for multiple explosive threats. This capability enables designers to analyze and select the optimal design solution that best meets the mission requirements of their site based on the anticipated explosive threat and their available construction budget. The scope of the developed model can be expanded in future research studies to consider and evaluate the consequences of explosive attacks inflicted on site personnel and operations.

\section{ACKNOWLEDGEMENTS}

The authors would like to thank Dr. Ahmet Soylemezoglu and the rest of the virtual Forward Operating Base team from the U.S. Army Engineer Research and Development Center, Construction Engineering Research Laboratory for their insightful comments and recommendations. The views expressed in this paper are those of the authors and do not reflect the official policy or position of the United States Air Force, Department of Defense, or the United States Government.

\section{REFERENCES}

[1] Hunter, R.J., Perkins, explosive states: AOAV's Explosive Violence Monitor 2014, AOAV, available at https://aoav.org.uk/2014/aoav-explosive-violence-data-2014/, 2015, (accessed 28 January 2016).

[2] Institute for Economics and Peace, 2015 Global terrorism impact: measuring and understanding the impact of terrorism, IEP, available at http://economicsandpeace. org/wp-content/uploads/2015/11/2015-Global-Terrorism-Index-Report.pdf, 2015, (accessed 12 December 2015).

[3] Federal Emergency Management Agency (FEMA), Reference manual to mitigate potential terrorist attacks against buildings, FEMA-426BIPS-06 Ed. 2. Washington, DC, 2011.

[4] Department of Defense (DoD), DoD minimum antiterrorism standards for buildings, UFC 4-010-01. Washington, DC, 2012.

[5] Rose, T.A., Smith, P.D. \& Mays, G.C., The effectiveness of walls designed for the protection of structures against airblast from high explosives. Proceedings of the Institution of Civil Engineers - Structures and Buildings, 110, pp. 78-85, 1995. https://doi.org/10.1680/istbu.1995.27306

[6] Rose, T.A., Smith, P.D. \& Mays, G.C., Protection of structures against airburst using barriers of limited robustness. Proceedings of the Institution of Civil Engineers - Structures and Buildings, 128, pp. 167-176, 1998.

http://dx.doi.org/10.1680/istbu.1998.30123 
[7] Beyer, M.E., Blast loads behind vertical walls, DTIC Document, 1986, available at: http://oai.dtic.mil/oai/oai?verb=getRecord\&metadataPrefix=html\&identifier= ADP005331 (accessed 29 January 2016).

[8] Scherbatiuk, K. \& Rattanawangcharoen, N., Experimental testing and numerical modeling of soil-filled concertainer walls. Engineering Structures, 30, pp. 3545-3554, 2008. https://doi.org/10.1016/j.engstruct.2008.05.030

[9] Bogosian, D. \& Piepenburg, D., Effectiveness of frangible barriers for blast shielding. In Proc. 17th Int. Symp. Mil. Asp. Blast Shock, Las Vegas, Nevada, USA, 2002.

[10] Chen, L., Zhang, L., Fang, Q. \& Mao, Y., Performance based investigation on the construction of anti-blast water wall. International Journal of Impact Engineering, 81, pp. 17-33, 2015.

https://doi.org/10.1016/j.ijimpeng.2015.03.003

[11] Khalafallah, A. \& El-Rayes, K., Minimizing construction-related security risks during airport expansion projects. Journal of Construction Engineering and Management, 134, pp. 40-48, 2008. http://dx.doi.org/10.1061/(ASCE)0733-9364(2008)134:1(40)

[12] Said, H. \& El-Rayes, K., Optimizing the planning of construction site security for critical infrastructure projects. Automation in Construction, 19, pp. 221-234, 2010. https://doi.org/10.1016/j.autcon.2009.10.005

[13] Li, Z., Shen, W., Xu, J. \& Lev, B., Bilevel and multi-objective dynamic construction site layout and security planning. Automation in Construction, 57, pp. 1-16, 2015. https://doi.org/10.1016/j.autcon.2015.04.011

[14] Deb, K., Pratap, A., Agarwal, S. \& Meyarivan, T., A fast and elitist multiobjective genetic algorithm: NSGA-II. Evolutionary Computation, 6, pp. 182-197, 2002. https://doi.org/10.1109/4235.996017

[15] Schuldt, S. \& El-Rayes, K., Quantifying blast effects on constructed facilities behind blast walls. Journal of Performance of Constructed Facilities, 31(4), 2017. http://dx.doi.org/10.1061/(ASCE)CF.1943-5509.0001015

[16] U.S. Army Corps of Engineers (USACE), Estimating damage to structures from terrorist bombs field operations guide, ETL 1110-3-495. Washington, DC, 1999.

[17] Khalafallah, A.M., Assessing the performance of the non-dominated sorting genetic algorithm in optimizing construction site planning. Computing in Civil and Building Engineering, 2014, pp. 1254-1261, 2014. http://dx.doi.org/10.1061/9780784413616.156

[18] U.S. Army Corps of Engineers (USACE), DoD Area Cost Factor, available at http://www. usace.army.mil/Cost-Engineering/Programming-Administration-and-Execution-SystemNe/, 2016 (accessed 21 February 2017). 